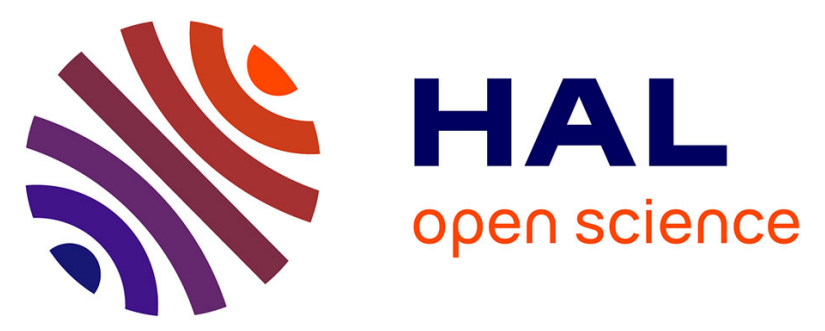

\title{
Response to: 'Spontaneous hypertensive rat exhibits bone and meniscus phenotypes of osteoarthritis: is it an appropriate control for MetS-associated OA?' by Chan and Wen
}

\author{
Chaohua Deng, Arnaud Bianchi, Nathalie Presle, David Moulin, Meriem \\ Koufany, Cécile Guillaume, Hervé Kempf, Anne Pizard
}

\section{To cite this version:}

Chaohua Deng, Arnaud Bianchi, Nathalie Presle, David Moulin, Meriem Koufany, et al.. Response to: 'Spontaneous hypertensive rat exhibits bone and meniscus phenotypes of osteoarthritis: is it an appropriate control for MetS-associated OA?' by Chan and Wen. Annals of the Rheumatic Diseases, 2018, 77 (5), pp.e26-e26. 10.1136/annrheumdis-2017-212003 . hal-02983106

\section{HAL Id: hal-02983106 \\ https://hal.univ-lorraine.fr/hal-02983106}

Submitted on 18 Feb 2022

HAL is a multi-disciplinary open access archive for the deposit and dissemination of scientific research documents, whether they are published or not. The documents may come from teaching and research institutions in France or abroad, or from public or private research centers.
L'archive ouverte pluridisciplinaire HAL, est destinée au dépôt et à la diffusion de documents scientifiques de niveau recherche, publiés ou non, émanant des établissements d'enseignement et de recherche français ou étrangers, des laboratoires publics ou privés. 
Response to "Spontaneous hypertensive rat exhibits bone and meniscus phenotypes of osteoarthritis: is it an appropriate control for MetS-associated OA?" by Chan and Wen

Chaohua Deng ${ }^{1,2}$, Arnaud Bianchi ${ }^{1,2}$, Nathalie Presle ${ }^{1,2}$, David Moulin ${ }^{1,2,3}$, Meriem Koufany ${ }^{1,2}$, Cécile Guillaume ${ }^{1,2}$, Hervé Kempf ${ }^{1,2, *, \$}$ and Anne Pizard ${ }^{2,3,4,5,,, \$}$

1 UMR 7365 CNRS-Université de Lorraine, IMoPA, Vandoeuvre-lès-Nancy, France.

2 Fédération de Recherche 3209, Vandoeuvre-lès-Nancy, France.

3 CHRU Nancy, Vandoeuvre-lès-Nancy, France.

4 CIC-P 1433 Inserm, Vandoeuvre-lès-Nancy, France.

5 UMRS U1116 Inserm-Université de Lorraine, DCAC, Vandoeuvre-lès-Nancy, France.

\$ joint senior authors

* Correspondence to:

Anne Pizard, Inserm U1116, CHRU Nancy, 4 rue du Morvan, Vandoeuvre-lès-Nancy 54500 France.

E-mail: anne.pizard@inserm.fr

Hervé Kempf, UMR 7365 CNRS-UL, IMoPA, 9 avenue de la Forêt de Haye, Vandoeuvre-lèsNancy 54500 France.

E-mail: herve.kempf@inserm.fr 
We thank Dr Chan and Dr Wen for their interest in our report ${ }^{1}$ and their resulting eLetter ${ }^{2}$. We fully agree that, among the different components of metabolic syndrome (MetS), hypertension has very recently been brought out as a critical feature in the development of osteoarthritis (OA) in humans. ${ }^{3,4}$ In these reports using either data from the Framingham OA study ${ }^{3}$ or the Osteoarthritis Initiative study $^{4}$, it has been emphasized that high blood pressure (diastolic or systolic respectively) was associated with increased incidence of radiographic knee OA.

In order to further experimentally investigate the actual role of hypertension in OA onset and development, Chan and colleagues describe in a yet unpublished study the development of OA features in the spontaneous hypertensive rat (SHR) model, a widely characterized model of systemic hypertension. ${ }^{2,5}$ Although the spontaneous hypertensive heart failure (SHHF) rat strain we employed is deriving from the SHR strain ${ }^{6}$ and suffers high blood pressure likewise, we were not able to identify OA-like lesions in our experimental model of $\mathrm{SHHF}^{+/+}$lean rats. ${ }^{1}$ These seeming discrepancies obtained in two related rat strains raised the concerns expressed by Chan and Wen on our recent results.

First, we respectfully disagree on the reservations put forward by Chen and Wen regarding our choice 'to study the mixed components of MetS in one model'. ${ }^{2}$ Indeed, in contrast to their study, ${ }^{2,5}$ our goal was purposely to explore the contribution of MetS as a whole, ${ }^{1}$ not to investigate a single and isolated MetS component, such as hypertension. Besides, since $\mathrm{SHHF}^{+/+}$and $\mathrm{SHHF}^{\mathrm{cp} / \mathrm{cp}}$ are both hypertensive, $, 7,8$ our results demonstrate the contribution of the metabolic components of MetS (obesity, dyslipidemia and insulin resistance) in knee OA development after adjustment for both age and blood pressure. Interestingly enough, the ability of eplerenone to prevent OA development ${ }^{1}$ without decreasing blood pressure ${ }^{8}$ further support the role of MetS as a whole, but not that of hypertension, in the OA lesions we observed in SHHF rats. ${ }^{1}$

Second, Chan and Wen suggest the inadequate use of $\mathrm{SHHF}^{+/+}$as proper controls in our study. ${ }^{2}$ Because both $\mathrm{SHHF}^{+/+}$and $\mathrm{SHHF}^{\mathrm{cp} / \mathrm{cp}}$ share the very same genetic background, $\mathrm{SHHF}^{+/+}$rats are very appropriate controls to compare to their littermate SHHF ${ }^{\mathrm{cp} / \mathrm{cp}}$ rats. By contrast, Wistar Kyoto (WK) used as control in Chan's study and SHR rats ${ }^{2,5}$ are more distant genetically and may differ greatly besides the normal vs. hypertensive status, which therefore may force caution in the proposed interpretations of the results. It stands however true that, in contrast to Chan and colleagues' results, ${ }^{2,5}$ we did not observe OA-like lesions in 12.5 month-old $\mathrm{SHHF}^{+/+}$knee joints, ${ }^{1}$ when they do report changes in bone and menisci, but no gross cartilage damage, in the knees of 9-month-old SHR rats. ${ }^{2,5}$ The apparent discrepancies may be attributable to the difference in the parameters examined to evaluate $O A$ in the two studies. Indeed, Chan et al. mostly evaluated changes in subchondral bone and meniscus, ${ }^{2,5}$ whereas we performed histopathological analysis of synovial and cartilage tissues. ${ }^{1}$ Although subchondral remodelling is critical in OA, we have not looked closely at the subchondral bone phenotype as clearly stated in our Letter. ${ }^{1}$ So, if as explained above we can exclude that hypertension does cause by itself OA-like phenotype in synovial and articular cartilage tissues of ${ }^{12.5} \mathrm{SHHF}^{+/+}$rats, we cannot rule out that, similar to what can be observed in SHR rats, SHHF ${ }^{+/+}$rats (and SHHF ${ }^{\mathrm{cp} / \mathrm{cp}}$ for that matter) do present significant remodelling of subchondral bone, a highly vascularized tissue, more prone to get affected by systemic pressure modification.

Based on Chan's eLetter comments ${ }^{2}$ and forthcoming study on SHR rats, ${ }^{5}$ we acknowledge that further investigation will be required to study and clarify the role of hypertension in SHHF rats as well. As a matter of fact, beside a comprehensive $\mu \mathrm{CT}$ analysis of the subchondral bone of both placeboand eplerenone-treated $\mathrm{SHHF}^{+/+}$and $\mathrm{SHHF}^{\mathrm{cp} / \mathrm{cp}}$ knees, we are also currently analyzing the knee phenotype of 18-month-old $\mathrm{SHHF}^{+/+}$rats. Compared to age-matched Wistar Kyoto normotensive rats as controls, this would allow to answer more directly Chan and Wen concern regarding the independent role played by hypertension in the SHHF model and probably corroborate their findings obtained in the SHR rats. ${ }^{2,5}$

Again, we appreciate the interest Chan and Wen show in our work and hope we adequately answered their concerns. 


\section{References}

1. Deng $\mathrm{C}$, Bianchi A, Presle $\mathrm{N}$ et al. Eplerenone treatment alleviates the development of joint lesions in a new rat model of spontaneous metabolic-associated osteoarthritis Ann Rheum Dis 2017 May 5. doi: 10.1136/annrheumdis-2016-210700.

2. Chan PB and Wen C. Spontaneous hypertensive rat exhibits bone and meniscus phenotypes of osteoarthritis: is it an appropriate control for MetS-associated OA? Ann Rheum Dis. 2017 Aug 10. doi: 10.1136/annrheumdis-2017-211995.

3. Niu J, Clancy M, Aliabadi P, et al. Metabolic Syndrome, Its Components, and Knee Osteoarthritis: The Framingham Osteoarthritis Study. Arthritis \& Rheumatology 2017; 69(6): 1194-1203.

4. Lo GH, McAlindon TE, Katz JN, et al. Systolic and Pulse Pressure Associate with Incident Knee Osteoarthritis: Data from the Osteoarthritis Initiative. Clinical Rheumatology, 2017 June 1 doi:10.1007/s10067-017-3656-z. [Epub ahead of print].

5. Chan PB, Yang WC, Wen CY, et al. Spontaneously Hypertensive Rat as a Novel Model of Comorbid Knee Osteoarthritis. Osteoarthritis and Cartilage 2017; 25: S319-S320.

6. McCune SA, Baker PB and Stills HF. SHHF/Mcc-c/i Rat: Model of Obesity, Non-insulin-dependent Diabetes, and Congestive Heart Failure ILAR News 1990; 32: 23-27.

7. Youcef G, Olivier A, L'Huillier CPJ, et al. Simultaneous characterization of metabolic, cardiac, vascular and renal phenotypes of lean and obese SHHF rats. PLoS ONE 2014;9:e96452.

8. Youcef G, Olivier A, Nicot N, et al. Preventive and chronic mineralocorticoid receptor antagonism is highly beneficial in obese SHHF rats. Br J Pharmacol 2016;173:1805-19.

\section{Contributions}

HK and AP : concept, writing; $C D, A B, N P, D M, M K, C G, H K$ and $A P$ : final approval. 